\title{
A comparative analysis of communal waste collection options for Mafikeng city council
}

\author{
F. R. Kizza Kadama \\ Faculty of Commerce and Administration, North West University, \\ Mafikeng Campus, South Africa
}

\begin{abstract}
This study examined the method of communal waste collection (CWC) practiced in Mafikeng city. It noted that a number of malpractices at $\mathrm{CWC}$ points have resulted in undesirable socio-economic impacts, which have prompted the need for the adoption of a new method of practice. The study proposed an alternative method and developed projected income statements, which were evaluated to determine whether to accept or reject the proposed method. All evaluations were in favour of adopting the proposed method. It was therefore the unequivocal recommendation of this study to reject the current method of CWC and accept the proposed method.
\end{abstract}

Keywords: cash inflow, projected income statements.

\section{Introduction}

The city of Mafikeng is located in Mafikeng Local Municipality (MLM) in the North West (NW) province of South Africa. According to MLM [1], it covers about $25 \%$ of the 3703 sq. $\mathrm{km}$ of the municipality. Over the years, the population of Mafikeng has steadily increased. Available statistics indicate that the population increased from 43395 in 1996 to 47887 in 2001, while the number of households increased from 11679 to 15921 during the same period (Statistics South Africa; [2] and [3]). From these statistics, it was computed that between 1996 and 2001, the population and number of households in Mafikeng city increased at a rate of about $2 \%$ and $7 \%$ per year, respectively.

The city is administered by the Mafikeng City Council (MCC) which provides its residents with municipal services such as waste removal, street lighting, water, electricity, sewerage services and storm water drainage (Statistics 
South Africa [3]). Kadama [4] notes that MCC was the only urban authority that provided both curb-side and communal waste removal services in the NW province. Curb-side collection was limited to domestic waste while CWC points were intended for garden waste only. The decision to provide a CWC service was taken in 2000 in consideration of the high numbers of low income residents in the Mmabatho and Montshioa areas who, due to lack of means to deliver their garden waste to landfills, resorted to littering. According MCC [5], there are about $90 \mathrm{CWC}$ points and 110 skips in the city. However, Kadama [4] observes that $\mathrm{CWC}$ points were not only used for the intended purpose of garden waste collection but were also wrongfully used as dumpsites for domestic waste, commercial waste from enterprises such as guesthouses operating in residential areas, building rubble and even dead pets. These malpractices continue to date (Van Vyk [6]). As a result, Mafikeng city experiences the following problems associated with communal waste collection that were identified in Kadama [4]:

1. Waste at CWC points, resulting from over-filled skips and littering is an aesthetic nuisance.

2. There is air pollution due to obnoxious and pungent odours that emanate from putrefying waste.

3. Neighbourhoods are infested with flies, rats and other pests that breed in the skips.

4. There is littering caused by scavengers as they rummage through the waste in the skips.

5. There is littering caused by wind from both stationery and in-transit skips.

These problems have negative socio-economic effects on residents. As a result, residents regularly vent their frustrations, especially due to the decline in property value, in both print and electronic media (Van Wyk [6]). In this respect, Mafikeng residents give credence to Zeiss [7] who argues that nuisance impacts from waste facilities can aggravate community resistance because odour, noise and visual impacts trigger more serious concerns about impacts on community health, image and property values.

Kadama [4] also notes that due to littering and other malpractices at CWC points, MCC had to acquire or hire tractor loader back-hoes (TLBs), tipper trucks and labourers to clean up after waste removal. These interventions, which had not been anticipated and as such were not budgeted for, have dire consequences for the city's scarce resources. In Kadama [4], it also emerged that the city's bye-laws on littering were outdated and ineffective under present circumstances and, worse still, the city council lacked resources to arrest and charge transgressors in courts of law. Clearly, the maintenance of operations at CWC has a debilitating effect on the city's meagre resources and the department of waste management should welcome viable solutions to this problem.

\subsection{Problem statement}

From the above observations, is clear that the current practice of waste disposal at CWC points in Mafikeng city is unsustainable as it creates an unhealthy 
environment, is an aesthetic nuisance, reduces property value and depletes the city council's scarce resources which could have been utilised for other pressing priorities. To crown it all, there is no hope for relief if the status quo persists since the existing bye-laws are ineffective and the city council lacks the wherewithal to implement the bye-laws even if these were amended. There is therefore an urgent need to adopt an alternative method of practice at CWC points in Mafikeng otherwise the malpractices will continue with impunity.

\subsection{Aim and purpose of the study}

The aim of the study was to apply capital budgeting techniques to justify the selection of an alternative method of practice at CWC points that is sustainable and complies with the city council's environmental management obligations. The purpose of the study was to highlight the unsustainable practice at CWC points in Mafikeng and advocate a sustainable alternative. The study addressed the following questions:

1. Was the CWC practice in Mafikeng sustainable?

2. Would it make economic sense to adopt the proposed method of practice at CWC points?

\subsection{The objectives of the paper}

The objectives were to:

1. Propose an alternative method of practice at CWC points that would be evaluated in comparison with the current method.

2. Develop projected operating cash inflows of the two methods under comparison.

3. Determine the payback period of each method.

4. Determine the annual incremental cash inflows if the proposed method were to be adopted.

\section{Methodology}

The study proposed the adoption of CWC points whose design would include the following features:

1. A concrete paved floor.

2. A ramp with a cantilever from which waste would be thrown into a skip placed on ground level.

3. A covered roof.

4. Chain link perimeter fence to enclose the facility and a lockable gate to limit after-hours access.

Each CWC point would be manned by an operator. Estimates of labour and material to construct one CWC point were obtained from GD Glad Designs in Mafikeng. 
The study viewed the CWC points as capital investments that were under consideration by the council in 2010 and the payback capital budgeting technique was applied to make a decision on which method to accept. The current method of CWC was evaluated as Investment 1 while the proposed method was evaluated as Investment 2. Data on prices of vehicles, fuel consumption and maintenance costs were obtained through quotations from suppliers and enquiries from a logistics management firm. Data were also collected in a self-administered interview with the manager of the city's municipal waste services. In determining the cash flow projections, the following assumptions and estimates were made:

1. Vehicle maintenance costs in the first year of operation were estimated to be $5 \%$ of the cost price of the vehicle.

2. Each vehicle consumed 601 of fuel per day.

3. There were 20 working days each month.

4. Vehicle maintenance costs increased annually by $12 \%$ to account for inflation and age.

5. All other expenses increased annually at a rate of $8 \%$ to account for inflation.

6. Each household would pay a CWC tariff of R10 in the first year which would increase by $8 \%$ annually.

7. In the period of the assessment, the population and number of households in Mafikeng would continue to increase annually at the rate of $2 \%$ and $7 \%$ respectively.

Given that there were 15921 households in Mafikeng in 2001and assuming the annual increment to be $7 \%$, equation (1) was used to compute the number of households in the city in 2010 .

where:

$$
\mathrm{HH}_{2}=\mathrm{HH}_{1}(1+\mathrm{r})^{\mathrm{n}}
$$

$\mathrm{HH}_{1}$ : Number of households in 2001

$\mathrm{HH}_{2}$ : Number of households in 2010

$\mathrm{r} \quad$ : Annual incremental rate

$\mathrm{n} \quad$ : Period in years

Equation (1) was applied to determine the number of households in Mafikeng in 2010.

$$
\begin{aligned}
& \mathrm{HH}_{2}=15921(1+0.07)^{9} \\
& \mathrm{HH}_{2}=29270
\end{aligned}
$$

The number of households in Mafikeng in 2010 was computed to be 29270 .

Equation (2) from Garrison and Noreen [7] was applied to compute the payback period for Investments 1 and 2.

$$
\text { Payback period }=\underline{\text { Investment required }}
$$

\section{Presentation of results}

Available data was used to develop cash flow projections for Investments 1 and 2 which are presented in Tables 1 and 2. 


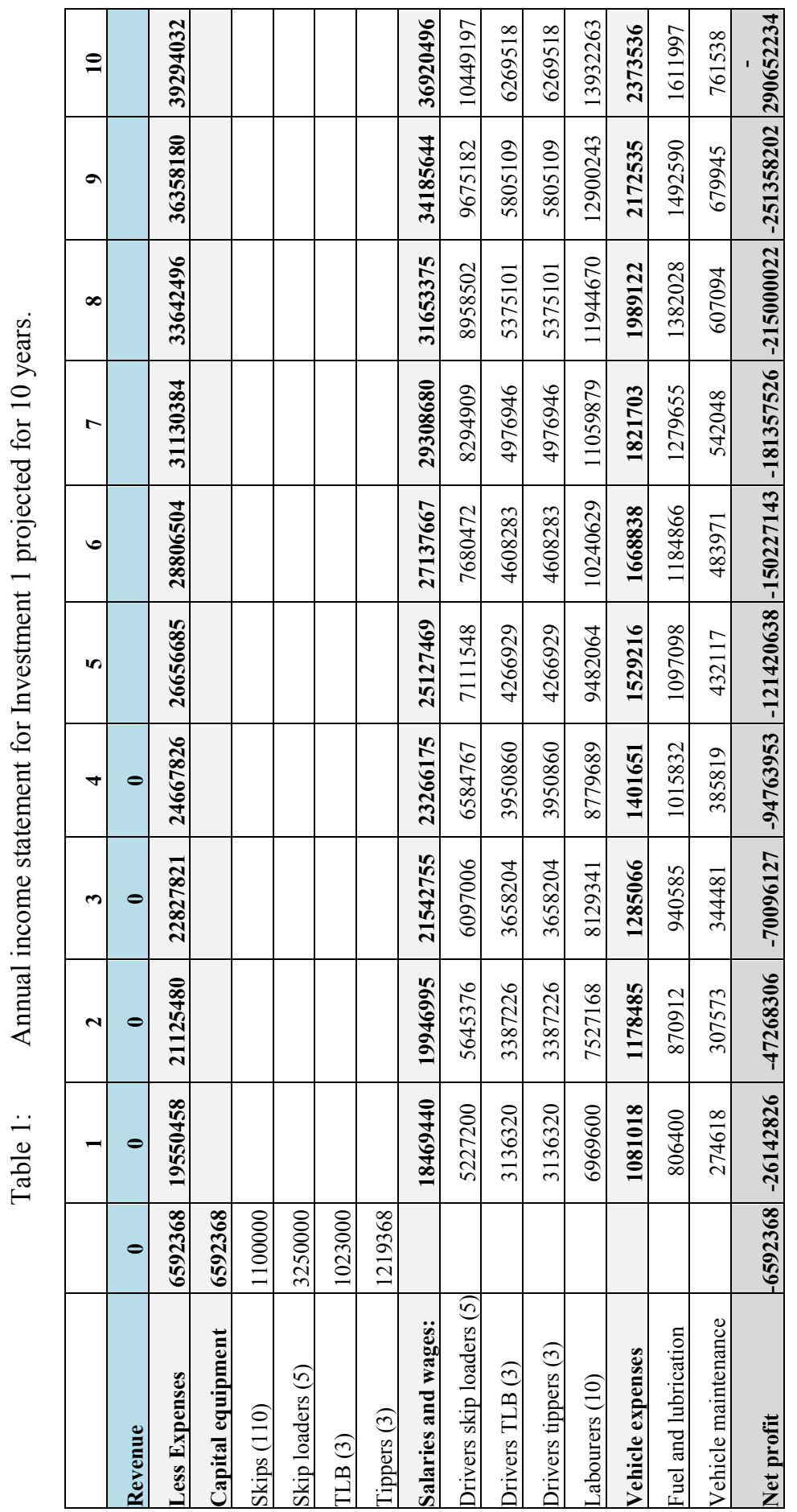




\begin{tabular}{|c|c|c|c|c|c|c|c|c|c|c|c|c|c|}
\hline$\Theta$ & 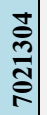 & $\begin{array}{l}\widetilde{1} \\
\hat{0} \\
\hat{\hat{\sigma}} \\
\hat{\sigma}\end{array}$ & & & & & $\begin{array}{c}\mathbb{N} \\
\stackrel{2}{B} \\
\infty \\
\infty\end{array}$ & $\begin{array}{c}\hat{0} \\
\hat{\infty} \\
0 \\
\tilde{m}\end{array}$ & $\begin{array}{c}0 \\
0 \\
0 \\
0 \\
\infty \\
\infty \\
\text { m } \\
\end{array}$ & 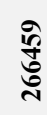 & $\begin{array}{l}8 \\
\stackrel{0}{n} \\
\stackrel{2}{2}\end{array}$ & \begin{tabular}{l}
8 \\
0 \\
\multirow{0}{0}{}
\end{tabular} & $\begin{array}{l}\bar{\sigma} \\
\tilde{n} \\
\tilde{\sigma} \\
\tilde{\sigma}\end{array}$ \\
\hline$a$ & 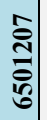 & 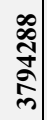 & & & & & 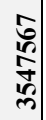 & 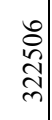 & 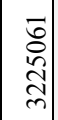 & $\begin{array}{l}\mathbb{N} \\
\underset{\delta}{+}\end{array}$ & $\begin{array}{l}\mathbb{t} \\
\vdots \\
0 \\
\infty \\
-2\end{array}$ & $\stackrel{\infty}{+}$ & $\underset{3}{\sqrt{3}}$ \\
\hline$\infty$ & 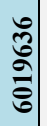 & 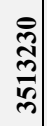 & & & & & 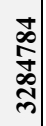 & 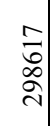 & $\left|\begin{array}{l}\hat{\sigma} \\
\mathbf{0} \\
2 \\
2\end{array}\right|$ & 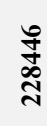 & 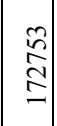 & $\begin{array}{l}\widetilde{D} \\
\tilde{b} \\
i n\end{array}$ & 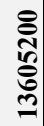 \\
\hline$r$ & $\begin{array}{l}\hat{n} \\
\frac{n}{\infty} \\
\text { in }\end{array}$ & $\begin{array}{l}\overline{\hat{\alpha}} \\
\hat{\tilde{d}} \\
\text { ले }\end{array}$ & & & & & 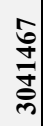 & $\begin{array}{l}\hat{a} \\
\hat{d} \\
\hat{v}\end{array}$ & 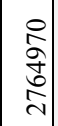 & 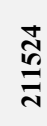 & 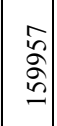 & $\begin{array}{l}\hat{6} \\
\stackrel{n}{n} \\
\end{array}$ & 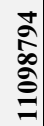 \\
\hline 0 & 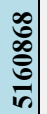 & 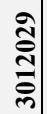 & & & & & $\begin{array}{c}n \\
\stackrel{n}{0} \\
\frac{0}{d}\end{array}$ & $\begin{array}{l}0 \\
\vdots \\
0 \\
\\
\end{array}$ & 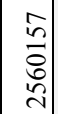 & $\begin{array}{l}0 \\
0 \\
0 \\
0\end{array}$ & $\begin{array}{l}\infty \\
\stackrel{\infty}{0} \\
\stackrel{\infty}{ \pm} \\
\pm\end{array}$ & 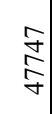 & 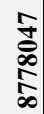 \\
\hline$n$ & $\begin{array}{l}\bar{\infty} \\
0 \\
0 \\
\stackrel{7}{f}\end{array}$ & $\begin{array}{l}n \\
\stackrel{n}{a} \\
\stackrel{\infty}{0} \\
\stackrel{0}{N}\end{array}$ & & & & & 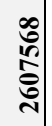 & $\begin{array}{l}\tilde{n} \\
\hat{2} \\
\hat{\imath}\end{array}$ & 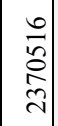 & $\underset{\infty}{\infty}$ & $\underset{n}{\stackrel{n}{n}}$ & $\begin{array}{l}\stackrel{ }{N} \\
\frac{y}{f}\end{array}$ & 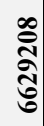 \\
\hline$\nabla$ & 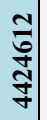 & 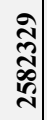 & & & & & $\begin{array}{l}\vec{J} \\
\stackrel{J}{J} \\
\stackrel{J}{J}\end{array}$ & $\begin{array}{l}\tilde{d} \\
\hat{d} \\
\stackrel{\vec{v}}{v}\end{array}$ & 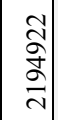 & $\frac{n}{\sigma}$ & $\begin{array}{l}\hat{2} \\
\hat{\mathbf{a}} \\
\mathrm{d}\end{array}$ & $\begin{array}{l}0 \\
2 \\
\hat{q}\end{array}$ & 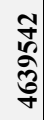 \\
\hline$m$ & 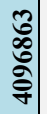 & 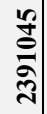 & & & & & 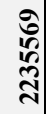 & 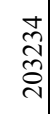 & $\mid \begin{array}{l}n \\
\tilde{2} \\
\hat{n} \\
\hat{\overbrace{}}\end{array}$ & 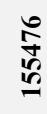 & $\begin{array}{l}\stackrel{n}{n} \\
\stackrel{n}{=}\end{array}$ & $\begin{array}{l}\hat{2} \\
\stackrel{n}{n}\end{array}$ & 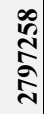 \\
\hline$N$ & ๙ิ & $\begin{array}{l}\overline{\tilde{n}} \\
\bar{\pi}\end{array}$ & & & & & 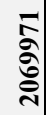 & $\begin{array}{c}\stackrel{\nabla}{a} \\
\infty \\
\infty\end{array}$ & 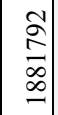 & $\begin{array}{l}\stackrel{\Xi}{\Xi} \\
\stackrel{m}{\Xi}\end{array}$ & $\begin{array}{l}\mathbb{J} \\
\infty \\
\infty \\
0 \\
0 \\
=\end{array}$ & $\begin{array}{c}\circ \\
\stackrel{0}{2} \\
n \\
n\end{array}$ & $\begin{array}{l}\stackrel{?}{ \pm} \\
\bar{g} \\
\Xi\end{array}$ \\
\hline- & 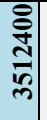 & 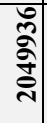 & & & & & 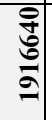 & $\begin{array}{l} \\
\stackrel{Y}{J} \\
\stackrel{I}{I}\end{array}$ & 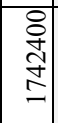 & స్心 & $\begin{array}{l}8 \\
8 \\
8 \\
\stackrel{0}{0}\end{array}$ & 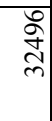 & 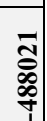 \\
\hline & $\theta$ & 0 & 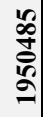 & \begin{tabular}{l}
8 \\
8 \\
0 \\
\hdashline
\end{tabular} & $\begin{array}{l}8 \\
8 \\
8 \\
0 \\
6\end{array}$ & $\begin{array}{c}n \\
0 \\
0 \\
0 \\
n \\
= \\
=\end{array}$ & & & & & & & 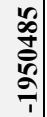 \\
\hline & 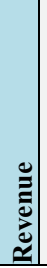 & 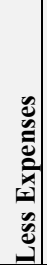 & 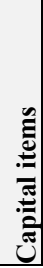 & 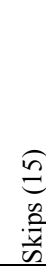 & 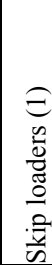 & 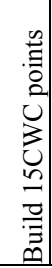 & 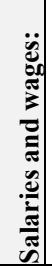 & 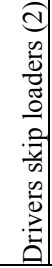 & 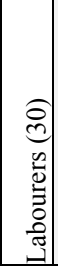 & 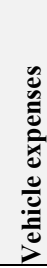 & 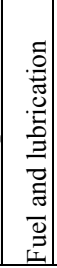 & 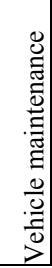 & 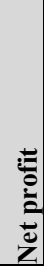 \\
\hline
\end{tabular}


Table 3: $\quad$ Incremental cash inflows for Investments 1 and 2.

\begin{tabular}{|c|c|c|c|}
\hline Year & Investment 2 & Investment 1 & Incremental \\
\hline 0 & -1950485 & -6592368 & 4641883 \\
\hline 1 & -488021 & -26142826 & 25654805 \\
\hline 2 & 1091440 & -47268306 & 48359746 \\
\hline 3 & 2797258 & -70096127 & 72893385 \\
\hline 4 & 4639542 & -94763953 & 99403495 \\
\hline 5 & 6629208 & -121420638 & 128049846 \\
\hline 6 & 8778047 & -150227143 & 159005190 \\
\hline 7 & 11098794 & -181357526 & 192456320 \\
\hline 8 & 13605200 & -215000022 & 228605222 \\
\hline 9 & 16312119 & -251358202 & 267670321 \\
\hline 10 & 19235591 & -290652234 & 309887825 \\
\hline
\end{tabular}

Information from the cash flow projections was used to develop the incremental cash inflows of Investment 1 and 2 that are presented in Table 3.

Equation (2) was applied to compute the payback period for the investments. Results showed that the payback period for Investment 1 approximated to negative infinity since the cash inflows exponentially decreased in value. The payback period for Investment 2 was computed to be 1.2 years.

\section{Discussion}

The findings of this study were evaluated on two bases:

1. Firstly, the investments were considered to be mutually exclusive alternatives and were evaluated on the basis of accept the best alternative and reject the other. The decision to accept or reject was based on results of cash flow analyses and the payback period.

2. Secondly, the Investment 2 was evaluated to determine whether it would be a viable replacement for Investment 1 . The decision whether to accept Investment 2 as a viable alternative was taken based on the analysis of incremental cash inflows.

An analysis of the income statement projections of Investments 1 and 2 is graphically illustrated in Figure 1.

From Figure 1, it is evident that Investment 1 would be a liability to the city as it consumes resources without generating profits throughout the period of assessment. On the other hand, it is evident that Investment 2 would start generating profit at the beginning of the second year and the profit would steadily increase on an annual basis up to the $10^{\text {th }}$ year of the projection. Based on this assessment, it was deemed appropriate to reject Investment 1 and accept Investment 2. 


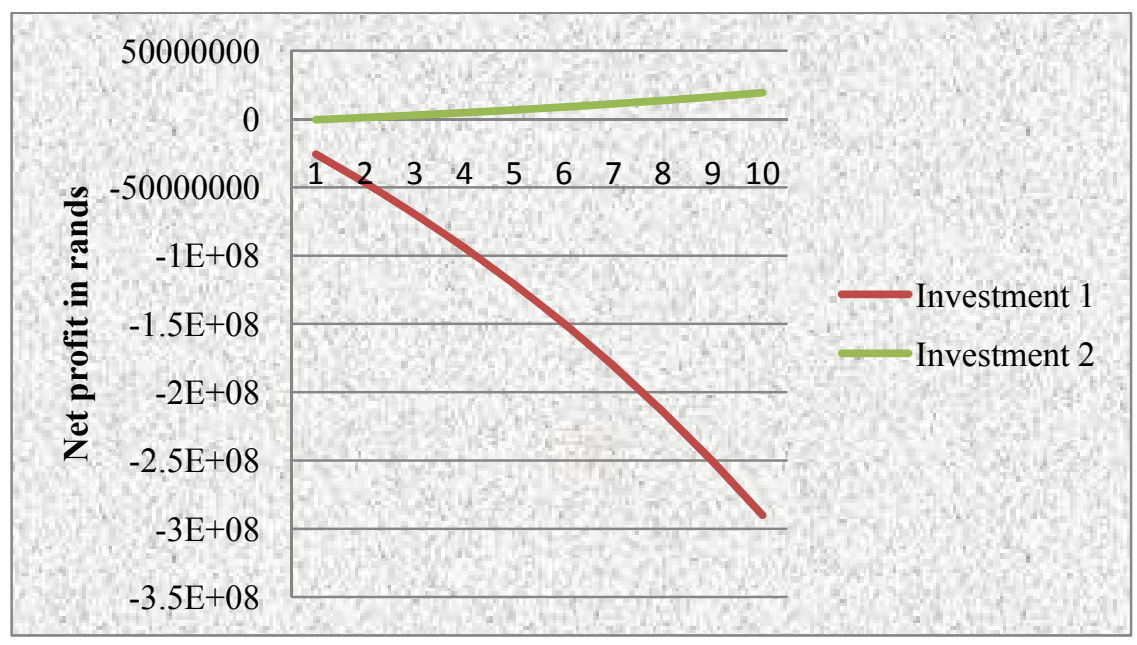

Figure 1: Investments' cash flows projected for 10 years.

Garrison and Noreen [7] define payback as the period taken for an investment to recoup its initial capital outlay from the revenue it generates. They assert that the shorter the payback period, the more desirable the investment. The payback period for Investment 1 approximates to negative infinity. This implies that Investment 1 was incapable of generating profit and would be an ever increasing burden to the city. Conversely, Investment 2 had a short payback period of 1.2 years. On the basis of this assessment, it was deemed logical to reject Investment 1 and accept Investment 2.

Incremental operating cash inflow assessments are helpful when making decisions on whether to replace one mode of operation with another (Gitman [9]). Incremental cash inflows may be positive, negative or zero. A positive value indicates that it may be worthwhile to change the method of operation; a zero value indicates that there will be no value added by adopting the new method of operation and a negative value indicates that change of operations will negatively impact on the organisation. An analysis of the incremental operating cash inflows of Investments 1 and 2 is illustrated in Figure 2.

From Figure 2 it is observable that the incremental operating cash inflows for Investments 1 and 2 are positive throughout the period of projection. It is also observable that the incremental inflows exponentially increase as time progresses. This indicates that replacing Investment 1 with Investment 2 would add value to the operations of the city and the benefits would progressively increase in value.

For purposes of frugality, this study proposed a basic design for adoption at the CWC points. However, the exponential incremental operating cash inflows realised in this study suggest that the benefits acruing from the selection of Investment 2 would afford the city council the luxury of high tech sophistication at $\mathrm{CWC}$ points such as mechanised hoppers to compact and direct waste into 


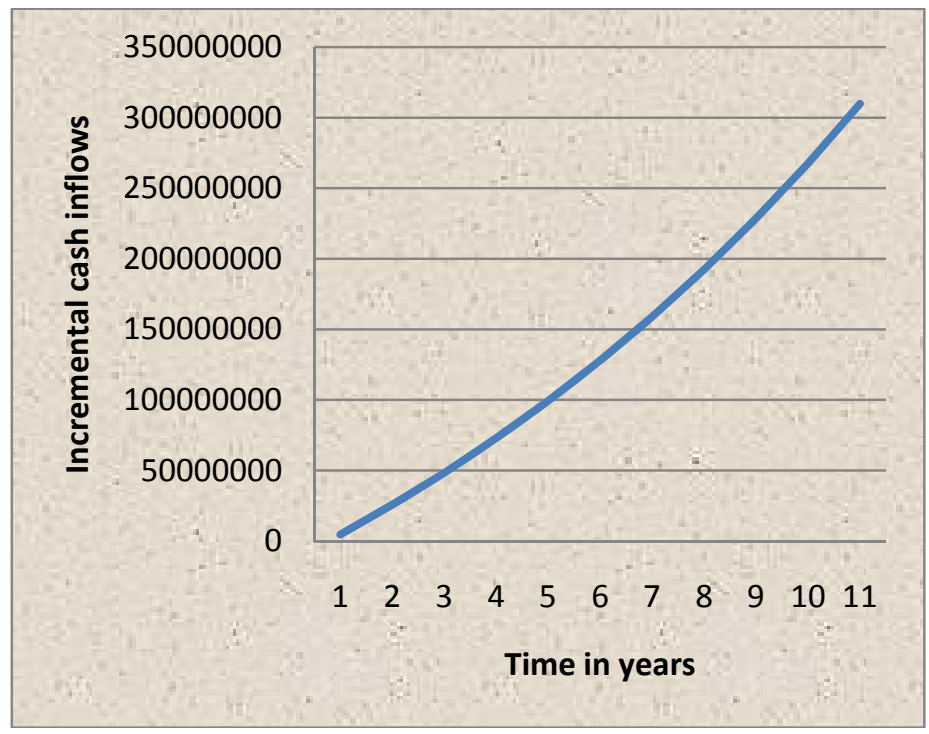

Figure 2: $\quad$ Incremental cash inflows for Investments 1 and 2.

skips and closed circuit television cameras (CCTV) to monitor malpractices at CWC points and other littering hotspots. Instalation of compacting hoppers at CWC points would reduce the trips by trucks to landfills thereby lowering transport and vehicle maintanence costs. Evidence provided by CCTVs would result in higher success rates in littering related prosecution. Also, through cooperative governance initiatives, evidence from CCTVs would prove essential in the fight against crime in the city.

\section{Conclusion}

The study evaluated Investments 1 and 2 based on the criteria outlined in section 4. In all instances the verdict was in favour of adopting Investment 2 rather than 1. On the basis of the decisions arived at in this study, it was deemed prudent that MCC should replace the present method of $\mathrm{CWC}$ with the one proposed in this study.

\section{References}

[1] MLM. 2010. Mafikeng Local Municipality. [Online]. Available: http://www.mafikeng.gov.za/

[2] Statistics South Africa. 2000. Census Super-cross Tables 1996. Statistics South Africa, Pretoria.

[3] Statistics South Africa. 2003. Census Super-cross Tables 2001. Statistics South Africa, Pretoria. 
224 Waste Management and the Environment V

[4] Kadama, F. R. K., 'An Analysis of the Generation and Management of Domestic Waste in the North West province of South Africa' PhD thesis, North West University, candidate.

[5] MCC (Mafikeng City Council). 2010. Personal communication. March 16, 2010. Manager Department of Waste Management.

[6] Van Wyk, F. 2010. 'Mafikeng sinking in waste', The Mail, 18 February, p12.

[7] Zeiss, C. Waste facility impacts on property value. Waste management and Research, 17(1), pp50-58

[8] Garrison, R. H. and Noreen, E. W. 1994.Managerial Accounting: Concepts for Planning, Control, Decision Making. $7^{\text {th }}$ edition. Irwin: Sydney

[9] Gitman, L. J. 2009. Principle of Managerial Finance. $12^{\text {th }}$ edition. Prentice Hall: Boston. 